\title{
Morphological aspects of blister aneurysms and nuances for surgical treatment
}

\author{
Michel W. Bojanowski, MD, FRCSC, ${ }^{1}$ Alexander G. Weil, MD, FRCSC, ${ }^{1}$ \\ Nancy McLaughlin, MD, PhD, FRCSC, ${ }^{1}$ Chiraz Chaalala, MD, ${ }^{1}$ FRCSC, Elsa Magro, MD, ${ }^{1}$ and \\ Jean-Yves Fournier, MD ${ }^{1,2}$
} 1'Division of Neurosurgery, Centre Hospitalier de I'Université de Montréal, Quebec, Canada; and 2Department of Neurosurgery,
Cantonal Hospital of St. Gallen, Switzerland

\begin{abstract}
OBJECT Blister aneurysms of the supraclinoid part of the internal carotid artery (ICA) are known for their high morbidity and mortality rates related to treatment, regardless of whether the treatment is surgical or endovascular. However, this grim prognosis is based on results that indiscriminately group all blister aneurysms together without taking into account the heterogeneous appearance of these lesions. The goal of this study was 2 -fold: to determine whether different blister aneurysm morphologies present different pitfalls, which would then require different surgical strategies, as well as to determine whether there are identifiable subgroups of these types of aneurysms based on morphology.

METHODS The authors reviewed the charts, cerebral catheter angiograms, surgical reports, and intraoperative videos of all ICA blister aneurysms treated surgically at the Centre Hospitalier de l'Université de Montréal from 2005 to 2012 to investigate whether there was a relationship between morphology and pitfalls, and whether different surgical strategies had been used according to these pitfalls. During this review process the authors noted 4 distinct morphological aspects. These 4 aspects led to a review of the English and French literature on blister aneurysms in which imaging was available, to determine whether other cases could also be classified into the same 4 subgroups based on these morphological aspects.
\end{abstract}

RESULTS The retrospective review of the authors' series of 10 patients allowed a division into 4 distinct subtypes: Type I (classic), Type II (berry-like), Type III (Iongitudinal), and Type IV (circumferential). These subtypes may at times be progressive stages in the arterial anomaly, and could represent a continuum. Each subtype described in this paper presented its own pitfalls and required specific surgical adaptations. Upon reviewing the literature the authors retained 35 studies involving a total of 61 cases of blister aneurysms, and all cases were able to be classified into 1 of these 4 distinct subtypes.

CONCLUSIONS Although they share some common characteristics, blister aneurysms may be divided into distinct subtypes, suggestive of a continuum. Such a classification with a detailed description of each type of blister aneurysm would allow for better recognition to anticipate complications during intervention and better assess the different treatment strategies according to the subtypes.

http://thejns.org/doi/abs/10.3171/2014.11.JNS141004

KEY WORDS blister aneurysm; clipping; subarachnoid hemorrhage; cerebral aneurysm morphology; vascular disorders; surgical technique

$\mathrm{B}$ LISTER aneurysms of the internal carotid artery (ICA) arise at a nonbranching site of the dorsal wall of

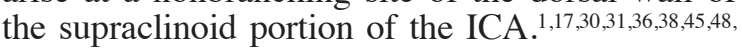
53,54 These types of aneurysms are rare and their management remains difficult. Whether the approach to these aneurysms is surgical or endovascular, the literature shows a high mortality and morbidity rate due to their fragile wall with its high rate of rupture during treatment. ${ }^{28,38,46,48} \mathrm{How}-$ ever, this grim prognosis is based on results that indis- criminately group all blister aneurysms together without taking into account the heterogeneous appearance of these lesions, thus making different treatment strategies difficult to assess. The first goal of this study was to ascertain whether blister aneurysm morphology played a role in the different pitfalls that may be encountered during surgery, and whether this morphology would require adapted surgical strategies. The second goal was to investigate whether any morphological differences could be categorized into

ABBREVIATION ICA = internal carotid artery.

SUBMITTED June 8, 2014. ACCEPTED November 5, 2014.

INCLUDE WHEN CITING Published online May 22, 2015; DOI: 10.3171/2014.11.JNS141004.

DISCLOSURE The authors report no conflict of interest concerning the materials or methods used in this study or the findings specified in this paper. 
distinct subtypes, which could be helpful in anticipating surgical complications.

\section{Methods}

We reviewed the charts, cerebral catheter angiograms, surgical reports, and intraoperative videos of all ICA blister aneurysms treated surgically at our institution by the senior author (M.W.B.) from 2005 to 2012, to determine whether there was a relationship between aneurysm morphology and pitfalls, and if that were true, how these differences influenced our surgical strategies. During this review we noted 4 distinct morphological aspects of blister aneurysms, which led us to review the English and French literature in which imaging was available, to investigate whether other cases could also be classified into 4 subgroups based on these morphological aspects.

Only cases of blister aneurysms, reported as such, involving the supraclinoid segment of the ICA arising at a nonbranching site, were retained. Carotid-ophthalmic aneurysms were excluded. We excluded cases described as blister aneurysms involving other vessels of the anterior or posterior circulation. We also excluded cases in the literature with insufficient radiological descriptions or those in which no images were available.

\section{Results}

In our series there were 10 patients who underwent operations during the study period who met the inclusion criteria. All 10 presented with the classic characteristics of blister aneurysms: they are very fragile, and arise at a nonbranching site of the supraclinoid segment of the ICA, most often in its anterior wall. ${ }^{28,38}$ However, in 1 of our cases, the aneurysm originated from its lateral wall. These aneurysms all arose at or close to the level of the posterior communicating artery. In 9 cases, they pointed toward the orbital part of the frontal lobe, and in 1 toward the temporal lobe. The common pitfalls associated with these general characteristics are that, due to their extremely fragile wall, they can easily rupture with the slightest manipulation during dissection or clip placement. Also, because they most often point toward the frontal lobe, they are susceptible to rupture during the approach, while the frontal lobe is being elevated.

\section{Blister Aneurysm Classification}

In our retrospective review in search of whether certain pitfalls could be associated with specific morpholo- gies and whether these differences warranted a different clip placement technique, we noted some correlations. We were able to categorize the aneurysms into 4 subgroups, which we named as types, and which could be recognized at times as different stages in an aneurysm's progression (Table 1). All aneurysms in our series and those we found in the literature could be readily classified into 1 of these 4 types (Table 2). 1,2,4,6,7,9,10,12-14,18-20,23-29,31-33,35,39-44,47,49-52,57 Each type presented distinctive surgical pitfalls, which required a different clip placement technique.

The first type (Type I) is simply a blister aneurysm with a small bulge with no neck, which may be easily missed on the first angiogram. Although it commonly arises from the anterior wall of the ICA, because of its small size, it is unlikely that its dome adheres to the frontal lobe even though arachnoid bands may attach it to the surrounding tissue. In addition, although the bulge is small, the diseased arterial wall extends longitudinally beyond the bulge on both sides. In our series, these types of lesions have been treated with right-angle clips applied parallel to the carotid artery, incorporating a thin band of tissue from the healthy arterial wall.

The second type (Type II) of blister aneurysm was the most commonly observed, and resembles a berry aneurysm. It also involves a part of the ICA wall, but with a sac having a large neck, although no larger than the diameter of the ICA. Being larger, this type of aneurysm is more likely to adhere to the frontal lobe. Even though it resembles a berry aneurysm, the surrounding wall of the ICA is also diseased. Clipping of these aneurysmal sacs in our series also required including a small portion of the healthy artery wall.

In the third type (Type III), the aneurysmal sac involves a significantly larger longitudinal portion of the ICA, defined as longer than the diameter of the ICA. In addition, as in the 2 previous types, the surrounding arterial wall is also diseased. Not surprisingly, because of its size, it may also adhere to the frontal lobe. Because of the extended longitudinal involvement of the ICA, in contrast with Types I and II, this type of lesion required a reconstruction of a very long segment of the parent artery by the application in tandem of 2 clips, both of which included a small band of healthy arterial tissue.

The fourth type (Type IV) involves almost all or all of the circumference of the ICA, thus showing an enlargement of the ICA on the angiogram. There is also a pouch associated with this enlargement, probably at the weakest point of the diseased parent artery. As in Types II and III, it may adhere to the surrounding brain tissue. A clipping-

TABLE 1. Subtypes of blister aneurysms in our series

\begin{tabular}{|c|c|c|c|c|}
\hline Type & Name & Description & No. of Cases & Strategy \\
\hline I & Classic & Part of wall, w/o sac & 2 & $\begin{array}{l}\text { Clipping of a bulged artery ex- } \\
\text { tending to its healthy portion }\end{array}$ \\
\hline II & Berry-like & $\begin{array}{l}\text { Part of wall w/ sac, in which the neck is not } \\
\text { longer than the diameter of the artery }\end{array}$ & 6 & $\begin{array}{l}\text { Clipping of sac including part of } \\
\text { healthy wall }\end{array}$ \\
\hline III & Longitudinal & $\begin{array}{l}\text { Long segment in which the neck is longer } \\
\text { than the diameter of the artery }\end{array}$ & 1 & $\begin{array}{l}\text { Parent artery reconstruction } \mathrm{w} / \\
\text { tandem clips }\end{array}$ \\
\hline IV & Circumferential & Circumferential & 1 & Clipping over wrapping \\
\hline
\end{tabular}


TABLE 2. Review of radiologically documented blister aneurysms in the literature (1996-2013)

\begin{tabular}{|c|c|c|c|c|c|c|}
\hline \multirow[b]{2}{*}{ Authors \& Year } & \multirow[b]{2}{*}{$\begin{array}{c}\text { No. of } \\
\text { Patients/Total }\end{array}$} & \multicolumn{2}{|c|}{ Epidemiology } & \multicolumn{3}{|c|}{ Morphology } \\
\hline & & Sex & Age & Location & $\begin{array}{l}\text { First Angiogram } \\
\text { Negative }\end{array}$ & Type \\
\hline \multirow[t]{2}{*}{ Kalani et al., 2013} & $2 / 18$ & $F$ & 46 & Anteromedial & & I \\
\hline & & M & 44 & Anterior & & 1 \\
\hline Park 2013 & 1 & $\mathrm{~F}$ & 58 & Anterior & & 1 \\
\hline Cho et al., 2012 & 1 & $\mathrm{~F}$ & 57 & Anterior & Yes & 1 \\
\hline Murai et al., 2012 & 1 & $\mathrm{~F}$ & 23 & Anterior & & 1 \\
\hline Yu-Tse et al., 2012 & 1 & M & 58 & Anteromedial & & II \\
\hline Haji et al., 2011 & 1 & $\mathrm{M}$ & 15 & Anterior & & II \\
\hline Horie et al., 2011 & 1 & $\mathrm{~F}$ & 34 & Anteromedial & & IV \\
\hline \multirow[t]{3}{*}{ Horiuchi et al., 2011} & $3 / 3$ & $\mathrm{~F}$ & 66 & Anterior & & II \\
\hline & & $\mathrm{F}$ & 57 & Anterior & Yes & 1 \\
\hline & & $\mathrm{F}$ & 29 & Anterior & & III \\
\hline \multirow[t]{2}{*}{ Matsubara et al., 2011} & $2 / 9$ & $\mathrm{~F}$ & 50 & Anterior & Yes & 1 \\
\hline & & M & 39 & Anterior & Yes & 1 \\
\hline Meckel et al., 2011 & $1 / 11$ & M & 56 & Posteromedial & & 1 \\
\hline \multirow[t]{3}{*}{ Regelsberger et al., 2011} & $3 / 3$ & $\mathrm{~F}$ & 49 & Anterior & & 1 \\
\hline & & $\mathrm{F}$ & 44 & Anterior & & III \\
\hline & & $\mathrm{F}$ & 61 & Posterior & & 1 \\
\hline \multirow[t]{4}{*}{ Gaughen et al., 2010} & $4 / 6$ & $\mathrm{~F}$ & 69 & Anteromedial & Yes & 1 \\
\hline & & $\mathrm{F}$ & 39 & Anteromedial & & II \\
\hline & & $\mathrm{F}$ & 46 & Posteromedial & Yes & 1 \\
\hline & & $\mathrm{F}$ & 41 & Anteromedial & & 1 \\
\hline \multirow[t]{4}{*}{ Lee et al., 2010} & $4 / 4$ & $\mathrm{~F}$ & 72 & Dorsal & & 1 \\
\hline & & M & 51 & Dorsal & & ॥ \\
\hline & & M & 61 & Anteromedial & Yes & 1 \\
\hline & & $\mathrm{F}$ & 52 & Dorsal & Yes & 1 \\
\hline \multirow[t]{7}{*}{ McLaughlin et al., 2010} & $7 / 7$ & M & 30 & & & 1 \\
\hline & & $\mathrm{F}$ & 33 & & & $\mid-\|$ ? \\
\hline & & $\mathrm{F}$ & 43 & & & \\
\hline & & M & 61 & & Yes & \\
\hline & & $\mathrm{F}$ & 47 & & Yes & \\
\hline & & $\mathrm{F}$ & 52 & & & \\
\hline & & M & 47 & & Yes & \\
\hline \multirow[t]{4}{*}{ Shimizu et al., 2010} & $4 / 8$ & $\mathrm{~F}$ & 56 & Anterior & Yes & II \\
\hline & & $\mathrm{F}$ & 49 & Anterior & & 1 \\
\hline & & $\mathrm{F}$ & 57 & Anterior & & III \\
\hline & & $\mathrm{F}$ & 38 & Anterior & & 1 \\
\hline \multirow[t]{2}{*}{ Lee et al., $2009^{28}$} & $2 / 18$ & $\mathrm{~F}$ & 61 & Anteromedial & & III \\
\hline & & $\mathrm{F}$ & 58 & Anterior & & II \\
\hline \multirow[t]{4}{*}{ Lee et al., $2009^{26}$} & $3 / 9$ & $\mathrm{~F}$ & 52 & Anteromedial & & II \\
\hline & & $\mathrm{F}$ & 54 & Anteromedial & & IV \\
\hline & & $\mathrm{F}$ & 52 & Anteromedial & & 1 \\
\hline & & $\mathrm{F}$ & 52 & Anteromedial & & III \\
\hline \multirow[t]{2}{*}{ Otani et al., 2009} & $2 / 9$ & $\mathrm{~F}$ & 40 & Posteromedial & & I \\
\hline & & $\mathrm{F}$ & 66 & Anterior & & III \\
\hline \multirow[t]{2}{*}{ Vashu et al., 2009} & $2 / 2$ & $\mathrm{~F}$ & 14 & Anterolateral & & I \\
\hline & & $\mathrm{F}$ & 48 & Lateral & & III \\
\hline Ahn et al., 2008 & 1 & $\mathrm{~F}$ & 64 & Anteromedial & & ॥ \\
\hline
\end{tabular}


TABLE 2. Review of radiologically documented blister aneurysms in the literature (1996-2013) (continued)

\begin{tabular}{|c|c|c|c|c|c|c|}
\hline \multirow[b]{2}{*}{ Authors \& Year } & \multirow[b]{2}{*}{$\begin{array}{c}\text { No. of } \\
\text { Patients/Total }\end{array}$} & \multicolumn{2}{|c|}{ Epidemiology } & \multicolumn{3}{|c|}{ Morphology } \\
\hline & & Sex & Age & Location & $\begin{array}{l}\text { First Angiogram } \\
\text { Negative }\end{array}$ & Type \\
\hline \multirow[t]{2}{*}{ Baskaya et al., 2008} & $2 / 4$ & M & 23 & Anteromedial & & ॥ \\
\hline & & M & 57 & Anterior & & IV \\
\hline Doorenbosch et al., 2008 & 1 & $\mathrm{~F}$ & 44 & Medial & & II \\
\hline \multirow[t]{2}{*}{ Korja et al., 2008} & $2 / 2$ & $\mathrm{M}$ & 48 & Anteromedial & & I \\
\hline & & $\mathrm{F}$ & 54 & Anteromedial & Yes & I \\
\hline Meling et al., 2008 & $1 / 14$ & M & 47 & Medial & & I \\
\hline Park et al., 2008 & $1 / 2$ & $\mathrm{~F}$ & 56 & Anteromedial & Yes & I \\
\hline Tekkök et al., 2008 & 1 & M & 43 & Medial & & II \\
\hline Park et al., 2007 & $1 / 7$ & $\mathrm{~F}$ & 31 & Dorsal & Yes & I \\
\hline Kim et al., 2007 & 1 & $\mathrm{~F}$ & 57 & Anteromedial & & III \\
\hline Joo et al., 2006 & 1 & M & 30 & Anteromedial & & II \\
\hline Kim et al., 2006 & 1 & $\mathrm{~F}$ & 42 & Anteromedial & Yes & I \\
\hline Islam et al., 2004 & 1 & M & 43 & Medial & & IV \\
\hline Tanoue et al., 2004 & 1 & $\mathrm{~F}$ & 63 & Anteromedial & & I \\
\hline \multirow[t]{2}{*}{ Pelz et al., 2003} & $2 / 2$ & $F$ & 34 & Anteromedial & & I \\
\hline & & $\mathrm{M}$ & 24 & Anterior & & I \\
\hline Wrobel et al., 2000 & 1 & - & 46 & Anteromedial & & I \\
\hline \multirow[t]{2}{*}{ Charbel et al., 1999} & $2 / 2$ & M & 54 & Anteromedial & & IV \\
\hline & & $\mathrm{F}$ & 48 & Medial & & I \\
\hline \multirow[t]{2}{*}{ Abe et al., 1998} & $2 / 6$ & $M$ & 56 & Anteromedial & & I \\
\hline & & $\mathrm{M}$ & 43 & Anteromedial & & I \\
\hline
\end{tabular}

over-wrapping technique was required. Table 1 presents the number of cases according to each type and the corresponding clip placement technique. An artistic representation of the 4 types is shown in Fig. 1.

There was no death in the series. There was no rebleeding nor any cerebrovascular infarctions. The modified Rankin Scale score at 3 months for all patients was 1 or 0 . Postoperative radiological CT angiograms obtained 1 year after the operation did not show any residual or recurrent aneurysms.

\section{Literature Review}

Reviewing the literature, and excluding patients from our series, we found 35 articles involving 61 cases of blister aneurysms with sufficient radiological documentation, after excluding those cases with the aforementioned exclusion criteria (Table 2). ${ }^{1,2,4,6,7,9-14,18-20,23,25-29,31-33,35,39-44,47,49-52,57}$ There often was a significant lack of detailed imaging description in many of the articles reviewed. Most of the articles focused on treatment strategies without providing sufficient morphological information.

These aneurysms were more common in women according to our literature review. Also generally, patients with blister aneurysms were younger than patients with berry aneurysms. ${ }^{47}$

In 12 cases, the first angiogram was negative or inconclusive, requiring a second angiogram 3 to 14 days later, revealing the presence of an aneurysm or a change in its morphological appearance. In all 61 cases, we were able to match the aneurysms according to our classification of 4 subtypes.

\section{Illustrative Cases}

\section{Type I: Classic blister aneurysm involving part of the wall of the ICA with a minimal bulge}

A 30-year-old man presented with a sudden onset of severe headache. On admission he was Hunt and Hess Grade I. His initial CT scan was normal. A lumbar puncture was suggestive of subarachnoid hemorrhage. Cerebral catheter angiography revealed a $2-\mathrm{mm}$ bulge on the anteromedial wall of the ophthalmic segment of the right ICA, consistent with a Type I blister aneurysm (Fig. 2A). A right frontotemporal craniotomy was performed to approach the blister aneurysm. From the beginning of the surgery, strategies were undertaken to relax the brain parenchyma to minimize brain retraction throughout surgery. After opening the dura, dissection was begun by opening the superficial sylvian fissure distal to proximal. The frontal lobe was gently raised to enable exposure of the chiasmatic cistern. The opening of the sylvian fissure was then continued up to the carotid cistern. Afterward, the arachnoid covering the chiasmatic and the carotid cisterns was opened. At this point, the bulge protruding from the anterior wall of the supraclinoid carotid segment was clearly visible. The aneurysm wall was very thin as whirls of blood could be seen through it. Part of the bulging wall appeared to contain a hemorrhage within it. This intraoperative observation 


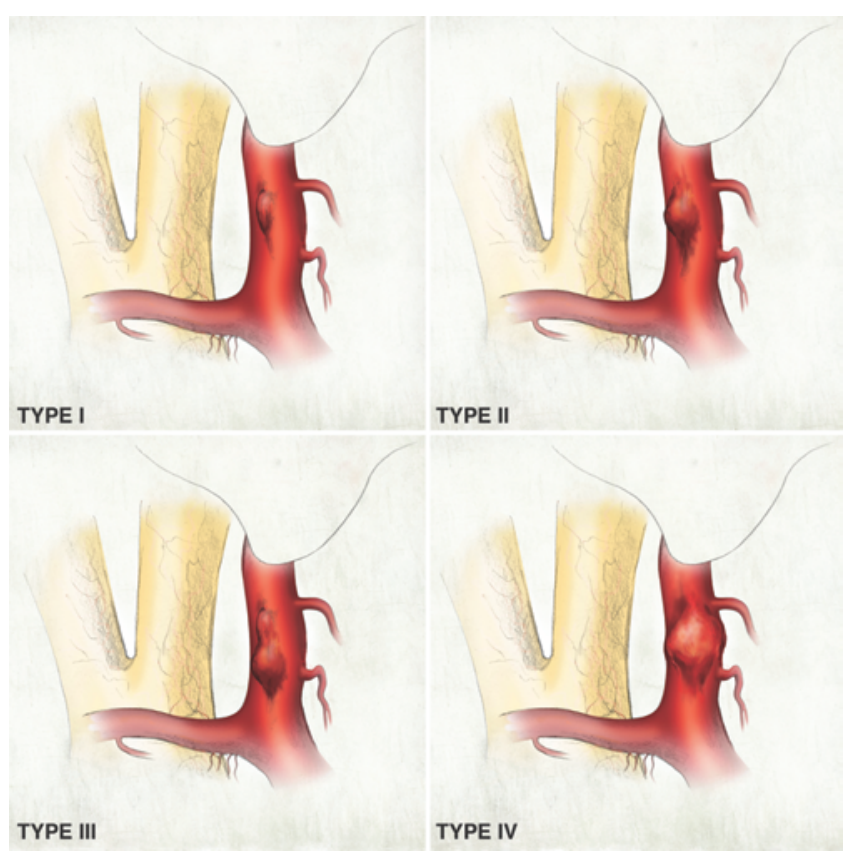

FIG. 1. Artist's illustration representing the 4 types of blister aneurysms: Type I, classic, with minimal bulge; Type II, berry-like, with large neck; Type III, longitudinal; and Type IV, circumferential, with involvement of a large portion of the ICA wall. Copyright Michel W. Bojanowski. Published with permission.

confirmed the Type I morphology suggested by the angiogram. The arachnoid strings around the carotid artery and the aneurysm were cut with microscissors, taking care not to put any traction on the aneurysm. The perforators arising from the involved carotid segment were protected throughout the dissection. At this point, temporary clips were applied to the parent vessel, proximally to the aneurysm and distally to the ophthalmic segment of the ICA, to ensure decompression of the carotid and to complete the aneurysmal dissection. A right-angle titanium clip was applied parallel to the carotid, deliberately including a part of the healthy wall, causing a small stenosis of the parent artery. The temporary clips were removed. The Doppler ultrasonography probe showed excellent blood flow in the carotid, distally to the clipped aneurysm. The anesthesiologist was then asked to raise the blood pressure to 150 $\mathrm{mm} \mathrm{Hg}$ systolic to ensure the stability of the clip. No hemorrhage or clip slippage was observed (Video 1).

VIDEO 1. Clip showing identification and treatment of a Type I blister aneurysm. Copyright Michel W. Bojanowski. Published with permission. Click here to view with Media Player. Click here to view with Quicktime.

Following surgery, the patient was neurologically intact. A CT scan showed no ischemic lesion. Postoperative angiography performed 8 days following subarachnoid hemorrhage showed complete exclusion of the blister aneurysm with mild stenosis of the right ICA (Fig. 2B).

\section{Type II: Berry-like blister aneurysm also involving a part of the ICA wall (but with a sac having a large neck)}

A 35-year-old woman was admitted after a subarachnoid hemorrhage (Hunt and Hess Grade II), confirmed by
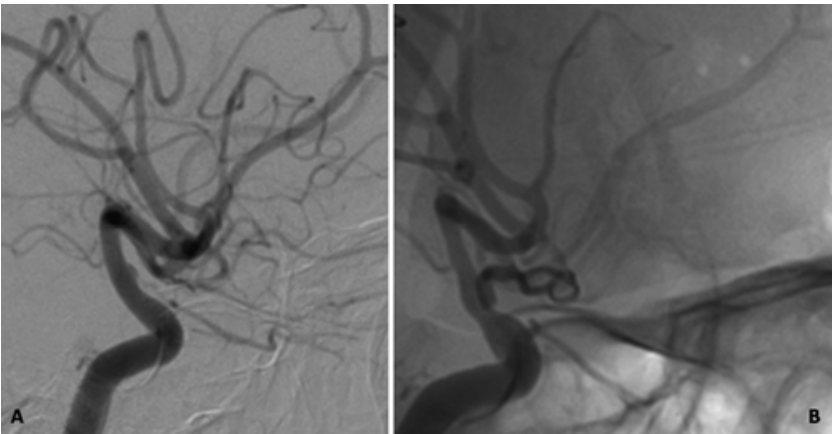

FIG. 2. Digital subtraction angiograms of a right-sided Type I blister aneurysm. A: Preoperative oblique view showing a minimal bulge on the dorsal wall of the ICA. B: Postoperative control image showing exclusion of the bulge.

a head CT scan. Catheter angiography revealed a blister aneurysm on the anteromedial wall of the ICA consistent with a Type II blister aneurysm (Fig. 3A). Through a frontotemporal craniotomy the aneurysm was exposed with the aforementioned precautions. The Type II morphology of the blister aneurysm was clearly noted, in agreement with the angiographic appearance. The aneurysm was clipped using a right-angle clip applied parallel to the ICA and incorporating part of its healthy wall (Video 2).

VIDEO 2. Clip showing identification and treatment of a Type II blister aneurysm. Copyright Michel W. Bojanowski. Published with permission. Click here to view with Media Player. Click here to view with Quicktime.

As in the previous case, the stability of the clip and the blood flow were assessed prior to closure.

The patient's postoperative course was uneventful. The postoperative catheter angiography confirmed complete exclusion of the aneurysm and the patency of the ICA (Fig. 3B).

\section{Type III: Longitudinal blister aneurysm involving a large longitudinal portion of the ICA wall, longer than the diameter of the ICA, with both an enlargement of the ICA and an overlying or an adjacent sac}

A 47-year-old woman presented with a Hunt and Hess
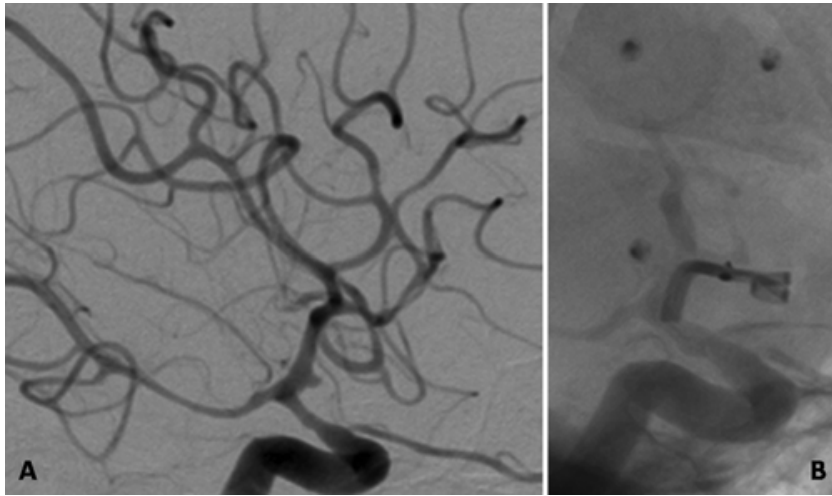

FIG. 3. Digital subtraction angiograms of a Type II blister aneurysm, with a hypoplastic anterior cerebral artery (not visible). A: Image showing the aneurysmal sac localized distal to the posterior communicating artery and pointing in the opposite direction. B: Postoperative control image showing exclusion of the aneurysmal sac. 
Grade II subarachnoid hemorrhage. Catheter angiography on admission was interpreted as normal. The examination was repeated 8 days later and revealed an enlargement of the posterior communicating segment of the ICA associated with a sac consistent with a Type III blister aneurysm (Fig. 4A). After exposure of the aneurysm using the technique already described, the aneurysm was clipped using 2 tandem clips incorporating part of the healthy wall (Video 3).

VIDEO 3. Clip showing identification and treatment of a Type III blister aneurysm. Copyright Michel W. Bojanowski. Published with permission. Click here to view with Media Player. Click here to view with Quicktime.

As usual, the stability of the clip and the blood flow are assessed prior to closure. As in the previous cases, microsurgical viewing confirmed what was already noted on angiography.

Postoperatively, the patient awoke neurologically intact and the postoperative catheter angiography revealed complete exclusion of the aneurysm without significant stenosis of the ICA (Fig. 4B).

\section{Type IV: Circumferential blister aneurysm involving a significant portion or the entire circumference of the ICA}

A 47-year-old man was admitted after sudden onset of severe headache due to a subarachnoid hemorrhage (Hunt and Hess Grade II). The digital subtraction angiogram revealed a complex aneurysm arising at the anteromedial wall of the ICA, consistent with a blister aneurysm (Fig. 5A). Exposure of the aneurysm revealed that a significant circumference of the ICA was involved, precluding complete clipping of the aneurysm without compromising the flow of the ICA. A clipping-over-wrapping technique was used without impairing the flow in the ICA or in its perforators (Video 4; Fig. 5C).

VIDEO 4. Clip showing identification and treatment of a Type IV blister aneurysm. Copyright Michel W. Bojanowski. Published with permission. Click here to view with Media Player. Click here to view with Quicktime.

Paying particular attention to the angiogram may suggest that a significant part of the arterial circumference is involved.

The patient was discharged 6 days after surgery without any new neurological deficits. Postoperative digital subtraction angiography revealed exclusion of the saccular component of the aneurysm (Fig. 5B).

Intraoperative photographs after clip placement in each type of blister aneurysm are shown in Fig. 6.

\section{Discussion}

Blister aneurysms are treacherous lesions because they are particularly difficult to treat. Complications affecting the outcome often arise during treatment itself. Although all patients in our small series obtained a good outcome, the literature reports a significantly high rate of mortality and morbidity, regardless of whether treatment was surgical or endovascular.1,28,38,46,48 These complications are mainly due to the fragile wall of the aneurysm, which can involve a significant part of the main vessel.

Although generally speaking, location and morphol-

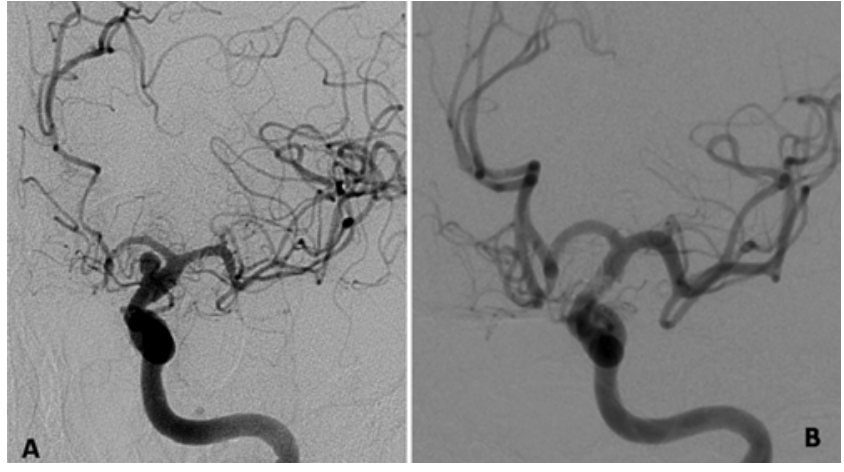

FIG. 4. Digital subtraction angiograms of a left-sided Type III blister aneurysm. A: Preoperative image demonstrating a sac involving a long portion of the ICA. B: Postoperative control image after tandem clip placement.

ogy (including size) are important factors when considering surgery, because this study of blister aneurysms only addresses those located on the ICA, morphology constitutes the main consideration regarding the risk of treatment. Blister aneurysms are known to be heterogeneous, thus presenting a broad spectrum of morphology, ${ }^{34}$ yet the literature groups all of these aneurysms together. To differentiate between them, it seems logical to classify them according to their morphology and thus ascertain whether different types of blister aneurysms present different pitfalls, which would require different treatment strategies.

By examining the imaging in all 71 cases (61 from the literature and 10 from our series), we were able to classify all of them into the 4 distinct groups described above (Table 2). This is not surprising, because this morphological classification considers whether the aneurysm involves all or part of the wall, and in the case of a partial involvement, it considers its size and length. These 4 subtypes may at times be stages in the evolutionary process, as observed regularly in the clinical setting. ${ }^{10,29,49}$ In fact, blister aneurysms are easily missed on the first angiography, where sometimes a questionable bulge can be retrospectively identified. In such cases, a second angiography performed 3 to 14 days later reveals their rapid evolution, making the diagnosis obvious (Table 2) and adding evidence that one may be involved with a continuum.

While recognizing that no classification system is unquestionably all encompassing, especially when it concerns a continuum in a disease process, this simple classification should nevertheless enable most, if not all, blister aneurysms to be readily defined. Perhaps future observation may expand this classification to include other characteristics that we have not yet encountered, such as multiple lesions.

Although in most cases the angiogram adequately reveals the morphology of the aneurysm, what is not readily visible is the state of the surrounding arterial tissue of the ICA. Consequently, some Type IV aneurysms may not be recognized as such. Of course, a better analysis of 3D angiography, and future improvements in imaging of the arterial wall, will lead to better preoperative reliance on this classification.

In our series the retrospective analysis of the angiograms revealed that in each case the angiogram correctly 

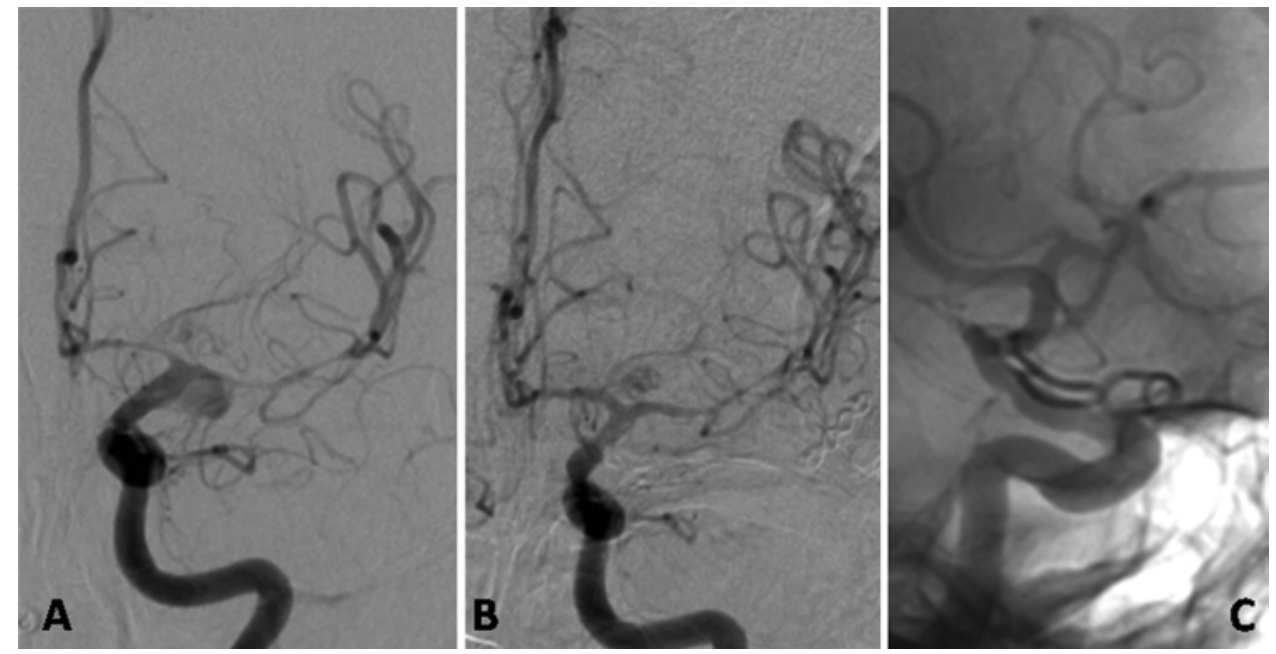

FIG. 5. Digital subtraction angiograms of a left-sided Type IV blister aneurysm. A: Preoperative image showing the aneurysmal sac and dilation of the ICA. B: Postoperative control image, frontal view, showing exclusion of the aneurysmal sac. C: Postoperative control image, oblique view, showing the position of the clip parallel to the ICA.

identified the type of blister aneurysm, which was confirmed upon microsurgical viewing. Nevertheless, given the limited number of cases in this series, more studies are needed to confirm the predictive value of the angiogram. Even so, this classification is useful for the clipping strategy with these types of aneurysms. In effect, intraoperative recognition of each type may allow us to approach these very fragile aneurysms more readily and more consistently, with the goal of improving prognosis. Therefore, it is mainly during surgery that this classification becomes most useful.

The rationale behind this classification is based on the particular pitfalls that may arise during surgery. Recognizing the particular type of aneurysm we are treating may help to evaluate its relationship to the surrounding structures. Moreover, the authors wish to emphasize that during surgical clip placement, the moment of clipping itself is most critical to the outcome. In fact, including too much of the healthy ICA wall in the clip may lead to stroke, whereas insufficient inclusion may result in intraoperative or immediate postoperative hemorrhage. Because the aneurysmal morphology determines the clip placement technique, it is important to distinguish the various subgroups, each of which requires a different clipping technique.

Regarding the surgical techniques and the pitfalls related to different types of blister aneurysms, there are general principles to be respected that apply to all blister aneurysms, and in addition there are type-specific clipping techniques.

\section{General Principles}

Blister aneurysms arise at a nonbranching site of the supraclinoid segment of the ICA, most often in its anterior wall. ${ }^{28,38}$ As such, they arise at or close to the level of the posterior communicating artery.22 Because these aneurysms arise on the anterior wall of the ICA, they point toward the orbital cortex. Any retraction of the frontal lobe to access the carotid proximal to the aneurysm could lead to tearing of the aneurysm, before any adequate exposure is obtained. Although adherence of the aneurysm to the frontal lobe is less likely for a Type I, which is a small bulge of the ICA, the possibility of tearing is certainly true for the other 3 types. One possible way of getting early proximal control without retraction is exposure of the carotid artery in the neck, which was the case for 1 patient in our own series. The exposure of the carotid artery in the neck is also important when the aneurysm extends very close to the distal ring of the ICA. In such situations, an anterior clinoidectomy might be necessary. Even so, the intracranial carotid artery should be approached with minimal brain retraction. To achieve this, we begin by opening the sylvian fissure from distal to proximal, and while approaching the supraclinoid carotid artery, the dissection is pursued on the lateral aspect of the carotid. This technique is contrary to the approach used for most berry aneurysms, which are found on the lateral side of the carotid artery. Nevertheless, one must still be aware of the possibility that

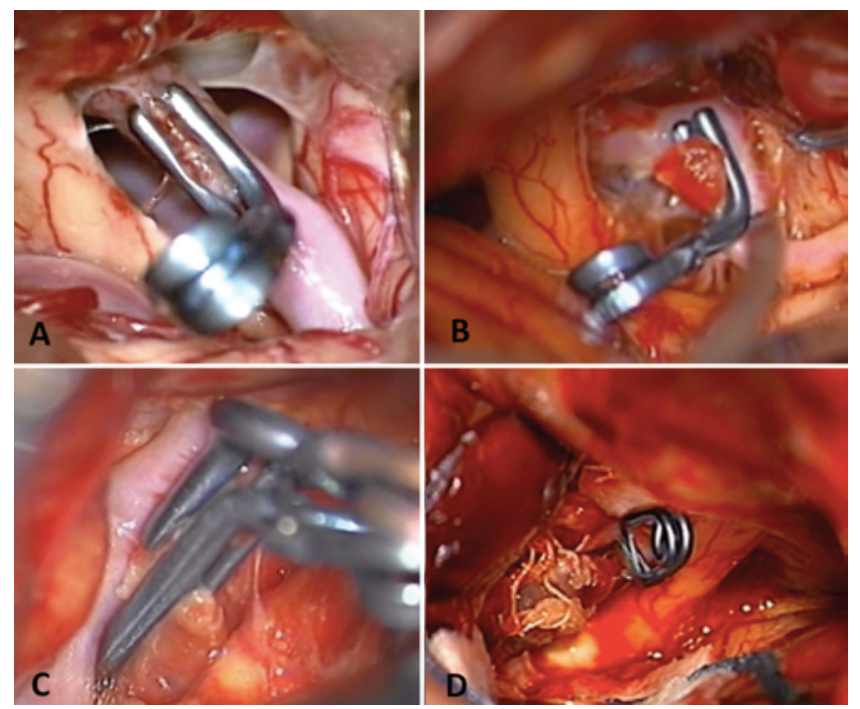

FIG. 6. Intraoperative images of clipped blister aneurysms according to type: Type I, classic (A); Type II, berry-like (B); Type III, longitudinal (C); and Type IV, circumferential (D). 
the dome may point toward the temporal lobe, as was the case in 1 of our patients. Obviously, in cases in which the aneurysm is facing the temporal lobe, the dissection occurs on the medial side of the ICA.

As in the surgical treatment of all aneurysms, brain relaxation is paramount. Apart from standard medical measures, depending on the severity of the subarachnoid hemorrhage, a ventriculostomy might be necessary, and the size of the craniotomy may vary. Exposure of the aneurysm itself and lysis of the arachnoid bands surrounding it is performed sharply and, when judged necessary, using a temporary clip on the proximal carotid artery. We do not perform subpial dissection.

\section{Clipping Techniques}

Because of the extremely fragile nature of blister aneurysms, clip placement must be performed using a temporary clip on the proximal ICA to reduce intraluminal pressure. In all cases, whenever possible, the clip must be applied with careful placement of the blades parallel to the parent artery.

Determining the type, preferably before or (if not possible) during the surgery, helps to choose the appropriate clip and clip placement technique to avoid unnecessary manipulation through trial and error of these very fragile aneurysms.

For Types I-III, a portion of the healthy wall must be included in the clip to avoid a rupture by clipping only the pathologically very thin wall of the lesion. Particular attention must be given to ensure that blood flow is not compromised by a significant stenosis. We assess this using a Doppler ultrasonography probe. The stability of the clip must be assessed by raising the blood pressure.

In both Types I and II, a right-angle clip is applied, including a portion of the healthy arterial wall. The reason why these 2 blister aneurysms are nevertheless distinct types in our classification system is to emphasize that even if Type II may look like a classic and more frequently occurring berry aneurysm, it is still a blister aneurysm and a portion of the healthy wall must be included in the clip. In addition, although the approach is the same for both Types I and II, one must anticipate the possibility that a Type II aneurysm may be adherent to the frontal lobe.

Type III lesions are potentially more challenging. This type is distinct from the previous 2 because it requires an arterial reconstruction due to the fact that it involves a much longer portion of the parent artery, longer than the diameter of the ICA. Consequently it may be more at risk for rupture or of ischemia during clip placement. Because a longer portion of the carotid artery is involved, clipping requires the use of tandem clips, while also incorporating part of the healthy wall.

For Type IV, the wrapping reinforces and protects the diseased arterial wall. In Type IV lesions, which requires the clipping-over-wrapping technique in which more manipulation is expected, one must be careful to avoid rupture. While wrapping, particular care must be taken to not injure the branches and perforators of the carotid artery. Also, during the clipping over the wrapping, blood flow in the carotid must not be compromised.

The detailed techniques described herein are those used by the senior author, who by no means suggests that they are the only way to proceed. The authors believe that when considering direct clip placement, referring to this classification may help to anticipate specific pitfalls and to plan appropriate surgical strategies.

Whichever clipping technique is used, it should address not only the hemispheric bulge, but also the affected ICA wall. For this reason, whenever possible, the authors prefer to include a portion of the healthy wall while clipping the blister aneurysm. Wrapping alone, without clipping the aneurysm, does not protect against bleeding. Although appropriate for Type IV aneurysms, which involve most if not all the wall of the ICA, indiscriminate clipping over wrapping may be potentially harmful. In effect, certainly for Types I and II, the wrapping material may prevent one from seeing the limit of the normal wall and thus impede proper clip placement. However, for some Type III blister aneurysms, where the long pathological segment of the wall curves under the hidden side of the ICA, clipping over wrapping may be the best choice.

Due to the significantly high mortality and morbidity rate following direct clip placement reported in the literature, ${ }^{20}$ occlusion of the parent artery and trapping of the aneurysm, with or without bypass, have been proposed by some authors. ${ }^{16,21,22,47,55}$ However, occlusion of a major vessel in an acute stage following subarachnoid hemorrhage is associated with poor prognosis. ${ }^{33}$ Also, a balloon test occlusion may be difficult to assess when the patient is suffering from the neurological effects of a ruptured aneurysm. As for endovascular techniques, coil embolization of blister aneurysms also remains problematic and not suitable because of its associated risk of rupture and ischemia. ${ }^{29,42}$ The use of flow diversion devices, such as the Pipeline (Covidien) and SILK (Balt Extrusion) devices, has been deemed a technically safe and feasible alternative. . $^{3,8,15,26,37,56}$ However, the aneurysm is not always immediately occluded, leading to the potential risk of rebleeding.,26,56 Moreover, the use of such devices requires the administration of antiplatelets, which may complicate the management of hydrocephalus. 5,26,56

Apart from having a concise repertoire of clip placement techniques corresponding to the types of blister aneurysms when opting for surgery, there is another reason why classifying them into distinct types may be of value. At the present time all these lesions are presented in the same category. Our observations of various morphological subgroups of these heterogeneous lesions may lead us to better predict which lesions pose a greater risk of treatment. The proposed classification system is also an attempt to eventually offer a prognostic tool that may, in the future, help in choosing among alternative treatments.

\section{Conclusions}

Blister aneurysms, which are heterogeneous, may be divided into 4 distinct morphological types, each of which present different pitfalls and require different surgical techniques. These 4 types may be considered progressive stages in a continuum of morphological changes. In the future, this classification may help to isolate the various factors involved in prognosis. 


\section{Acknowledgments}

We wish to thank Dr. Doortje Engel and Mrs. Lucyna Szpak for their assistance in editing the manuscript.

\section{References}

1. Abe M, Tabuchi K, Yokoyama H, Uchino A: Blood blisterlike aneurysms of the internal carotid artery. J Neurosurg 89:419-424, 1998

2. Ahn JY, Cho JH, Jung JY, Lee BH, Yoon PH: Blister-like aneurysms of the supraclinoid internal carotid artery: challenging endovascular treatment with stent-assisted coiling. J Clin Neurosci 15:1058-1061, 2008

3. Aydin K, Arat A, Sencer S, Hakyemez B, Barburoglu M, Sencer A, et al: Treatment of ruptured blood blister-like aneurysms with flow diverter SILK stents. J Neurointerv Surg, 2014

4. Başkaya MK, Ahmed AS, Ateş O, Niemann D: Surgical treatment of blood blister-like aneurysms of the supraclinoid internal carotid artery with extracranial-intracranial bypass and trapping. Neurosurg Focus 24(2):E13, 2008

5. Chalouhi N, Zanaty M, Tjoumakaris S, Gonzalez LF, Hasan D, Kung D, et al: Treatment of blister-like aneurysms with the pipeline embolization device. Neurosurgery 74:527-532, 2014

6. Charbel FT, Gonzales-Portillo G, Hoffman W, Cochran E: Distal internal carotid artery pseudoaneurysms: technique and pitfalls of surgical management: two technical case reports. Neurosurgery 45:643-649, 1999

7. Cho TG, Hwang SN, Nam TK, Park SW: Salvage surgical treatment for failed endovascular procedure of a blood blister-like aneurysm. J Cerebrovasc Endovasc Neurosurg 14:99-103, 2012

8. Çinar C, Bozkaya H, Oran I: Endovascular treatment of cranial aneurysms with the pipeline flow-diverting stent: preliminary mid-term results. Diagn Interv Radiol 19:154-164, 2013

9. Doorenbosch X, Harding M: Primary treatment of a bloodblister-like aneurysm of the internal carotid artery with Guglielmi detachable coil embolisation. J Clin Neurosci 15:1276-1279, 2008

10. Gaughen JR Jr, Hasan D, Dumont AS, Jensen ME, McKenzie J, Evans AJ: The efficacy of endovascular stenting in the treatment of supraclinoid internal carotid artery blister aneurysms using a stent-in-stent technique. AJNR Am J Neuroradiol 31:1132-1138, 2010

11. Gaughen JR Jr, Raghavan P, Jensen ME, Hasan D, Pfeffer AN, Evans AJ: Utility of CT angiography in the identification and characterization of supraclinoid internal carotid artery blister aneurysms. AJNR Am J Neuroradiol 31:640-644, 2010

12. Haji FA, Boulton MR, de Ribaupierre S: Blister-like supraclinoid internal carotid artery pseudoaneurysm in a 15-year-old male: case report and review of the literature. Pediatr Neurosurg 47:449-454, 2011

13. Horie N, Morikawa M, Fukuda S, Hayashi K, Suyama K, Nagata I: Detection of blood blister-like aneurysm and intramural hematoma with high-resolution magnetic resonance imaging. J Neurosurg 115:1206-1209, 2011

14. Horiuchi T, Kusano Y, Yako T, Murata T, Kakizawa Y, Hongo K: Ruptured anterior paraclinoid aneurysms. Neurosurg Rev 34:49-55, 2011

15. Hu YC, Chugh C, Mehta H, Stiefel MF: Early angiographic occlusion of ruptured blister aneurysms of the internal carotid artery using the Pipeline embolization device as a primary treatment option. J Neurointerv Surg 6:740-743, 2014

16. Ishikawa T, Mutoh T, Nakayama N, Yasuda H, Nomura M, Kazumata K, et al: Universal external carotid artery to proximal middle cerebral artery bypass with interposed radial artery graft prior to approaching ruptured blood blister-like aneurysm of the internal carotid artery. Neurol Med Chir (Tokyo) 49:553-558, 2009
17. Ishikawa T, Nakamura N, Houkin K, Nomura M: Pathological consideration of a "blister-like" aneurysm at the superior wall of the internal carotid artery: case report. Neurosurgery 40:403-406, 1997

18. Islam MS, Manabe H, Hasegawa S, Takemura A, Nagahata M: Successful staged treatment for ruptured blister-like dissecting aneurysm of the intracranial internal carotid artery: acute GDC embolization for the blister-like aneurysm followed by proximal occlusion with extracranial-intracranial bypass in the chronic stage. Minim Invasive Neurosurg 47:165-168, 2004

19. Joo SP, Kim TS, Moon KS, Kwak HJ, Lee JK, Kim JH, et al: Arterial suturing followed by clip reinforcement with circumferential wrapping for blister-like aneurysms of the internal carotid artery. Surg Neurol 66:424-429, 2006

20. Kalani MY, Zabramski JM, Kim LJ, Chowdhry SA, Mendes GA, Nakaji P, et al: Long-term follow-up of blister aneurysms of the internal carotid artery. Neurosurgery 73:1026-1033, 2013

21. Kamijo K, Matsui T: Acute extracranial-intracranial bypass using a radial artery graft along with trapping of a ruptured blood blister-like aneurysm of the internal carotid artery. Clinical article. J Neurosurg 113:781-785, 2010

22. Kazumata K, Nakayama N, Nakamura T, Kamiyama H, Terasaka S, Houkin K: Changing treatment strategy from clipping to radial artery graft bypass and parent artery sacrifice in patients with ruptured blister-like internal carotid artery aneurysms. Neurosurgery 10 (Suppl 1):66-73, 2014

23. Kim BM, Chung EC, Park SI, Choi CS, Won YS: Treatment of blood blister-like aneurysm of the internal carotid artery with stent-assisted coil embolization followed by stent-within-a-stent technique. Case report. J Neurosurg 107:12111213,2007

24. Kim JH, Kwon TH, Kim JH, Park YK, Chung HS: Internal carotid artery dorsal wall aneurysm with configurational change: are they all false aneurysms? Surg Neurol 66:441443, 2006

25. Korja M, Rautio R, Valtonen S, Haapanen A: Primary treatment of ruptured blood blister-like aneurysms with stentassisted coil embolization: report of two cases. Acta Radiol 49:180-183, 2008

26. Lee BH, Kim BM, Park MS, Park SI, Chung EC, Suh SH, et al: Reconstructive endovascular treatment of ruptured blood blister-like aneurysms of the internal carotid artery. J Neurosurg 110:431-436, 2009

27. Lee CC, Hsieh TC, Wang YC, Lo YL, Lee ST, Yang TC: Ruptured symptomatic internal carotid artery dorsal wall aneurysm with rapid configurational change. Clinical experience and management outcome: an original article. Eur J Neurol 17:1277-1284, 2010

28. Lee JW, Choi HG, Jung JY, Huh SK, Lee KC: Surgical strategies for ruptured blister-like aneurysms arising from the internal carotid artery: a clinical analysis of 18 consecutive patients. Acta Neurochir (Wien) 151:125-130, 2009

29. Matsubara N, Miyachi S, Tsukamoto N, Izumi T, Naito $\mathrm{T}$, Haraguchi K, et al: Endovascular coil embolization for saccular-shaped blood blister-like aneurysms of the internal carotid artery. Acta Neurochir (Wien) 153:287-294, 2011

30. McLaughlin N, Laroche M, Bojanowski MW: Blister-like aneurysms of the internal carotid artery - management considerations. Neurochirurgie 58:170-186, 2012

31. McLaughlin N, Laroche M, Bojanowski MW: Surgical management of blood blister-like aneurysms of the internal carotid artery. World Neurosurg 74:483-493, 2010

32. Meckel S, Singh TP, Undrén P, Ramgren B, Nilsson OG, Phatouros C, et al: Endovascular treatment using predominantly stent-assisted coil embolization and antiplatelet and anticoagulation management of ruptured blood blister-like aneurysms. AJNR Am J Neuroradiol 32:764-771, 2011 
33. Meling TR, Sorteberg A, Bakke SJ, Sletteb $\varnothing$ H, Hernesniemi J, Sorteberg W: Blood blister-like aneurysms of the internal carotid artery trunk causing subarachnoid hemorrhage: treatment and outcome. J Neurosurg 108:662-671, 2008

34. Mitha AP, Spetzler RF: Blister-like aneurysms: an enigma of cerebrovascular surgery. World Neurosurg 74:444-445, 2010

35. Murai Y, Mizunari T, Umeoka K, Tateyama K, Kobayashi S, Teramoto A: Ischemic complications after radial artery grafting and aneurysmal trapping for ruptured internal carotid artery anterior wall aneurysm. World Neurosurg 77:166-171, 2012

36. Nakagawa F, Kobayashi S, Takemae T, Sugita K: Aneurysms protruding from the dorsal wall of the internal carotid artery. J Neurosurg 65:303-308, 1986

37. Nerva JD, Morton RP, Levitt MR, Osbun JW, Ferreira MJ, Ghodke BV, et al: Pipeline Embolization Device as primary treatment for blister aneurysms and iatrogenic pseudoaneurysms of the internal carotid artery. J Neurointerv Surg 7:21-216, 2015

38. Ogawa A, Suzuki M, Ogasawara K: Aneurysms at nonbranching sites in the surpaclinoid portion of the internal carotid artery: internal carotid artery trunk aneurysms. Neurosurgery 47:578-586, 2000

39. Otani N, Takasato Y, Masaoka H, Hayakawa T, Yoshino Y, Yatsushige $\mathrm{H}$, et al: Clinical and radiological findings and surgical management of ruptured aneurysms at the nonbranching sites of the internal carotid artery. J Clin Neurosci 16:1018-1023, 2009

40. Park EK, Ahn JS, Kwon H, Kwun BD: Result of extracranialintracranial bypass surgery in the treatment of complex intracranial aneurysms: outcomes in 15 cases. J Korean Neurosurg Soc 44:228-233, 2008

41. Park J: Maintenance of cerebral blood flow during microsuture repair of the superior wall of the intracranial internal carotid artery. World Neurosurg 80:436.e1-436.e5, 2013

42. Park JH, Park IS, Han DH, Kim SH, Oh CW, Kim JE, et al: Endovascular treatment of blood blister-like aneurysms of the internal carotid artery. J Neurosurg 106:812-819, 2007

43. Pelz DM, Ferguson GG, Lownie SP, Kachur E: Combined endovascular/neurosurgical therapy of blister-like distal internal carotid aneurysms. Can J Neurol Sci 30:49-53, 2003

44. Regelsberger J, Matschke J, Grzyska U, Ries T, Fiehler J, Köppen J, et al: Blister-like aneurysms - a diagnostic and therapeutic challenge. Neurosurg Rev 34:409-416, 2011

45. Sekula RF, Jr., Cohen DB, Quigley MR, Jannetta PJ: Primary treatment of a blister-like aneurysm with an encircling clip graft: technical case report. Neurosurgery 59:ONSE168; 2006

46. Shigeta H, Kyoshima K, Nakagawa F, Kobayashi S: Dorsal internal carotid artery aneurysms with special reference to angiographic presentation and surgical management. Acta Neurochir (Wien) 119:42-48, 1992

47. Shimizu H, Matsumoto Y, Tominaga T: Non-saccular aneurysms of the supraclinoid internal carotid artery trunk causing subarachnoid hemorrhage: acute surgical treatments and review of literatures. Neurosurg Rev 33:205-216, 2010

48. Sim SY, Shin YS, Cho KG, Kim SY, Kim SH, Ahn YH, et al: Blood blister-like aneurysms at nonbranching sites of the internal carotid artery. J Neurosurg 105:400-405, 2006

49. Tanoue S, Kiyosue H, Matsumoto S, Yamashita M, Nagatomi H, Mori H: Ruptured "blisterlike" aneurysm with a pseudoaneurysm formation requiring delayed intervention with endovascular coil embolization. Case report. J Neurosurg 101:159-162, 2004

50. Tekkök IH, Bakar B: Ruptured blister-like aneurysm of distal internal carotid artery: a distinct entity. Turk Neurosurg 18:439-445, 2008

51. Vashu R, Tan S, Wong AS: Microsuture repair of intra-oper- ative ruptures of cerebral aneurysms of the internal carotid artery. J Clin Neurosci 16:960-962, 2009

52. Wrobel CJ, Taubman K: Blood-blister-like aneurysms. J Neurosurg 92:1076-1077, 2000

53. Yanagisawa T, Mizoi K, Sugawara T, Suzuki A, Ohta T, Higashiyama N, et al: Direct repair of a blisterlike aneurysm on the internal carotid artery with vascular closure staple clips. Technical note. J Neurosurg 100:146-149, 2004

54. Yanaka K, Meguro K, Nose T: Repair of a tear at the base of a blister-like aneurysm with suturing and an encircling clip: technical note. Neurosurgery 50:218-221, 2002

55. Yang K, Ahn JS, Park JC, Kwon DH, Kwun BD, Kim CJ: The efficacy of bypass surgery using short interposition graft for the treatment of intracranial complex aneurysm. World Neurosurg 83:197-202, 2014

56. Yoon JW, Siddiqui AH, Dumont TM, Levy EI, Hopkins LN, Lanzino G, et al: Feasibility and safety of pipeline embolization device in patients with ruptured carotid blister aneurysms. Neurosurgery 75:419-429, 2015

57. Yu-Tse L, Ho-Fai W, Cheng-Chi L, Chu-Mei K, Yi-Chou W, Tao-Chieh Y: Rupture of symptomatic blood blister-like aneurysm of the internal carotid artery: clinical experience and management outcome. Br J Neurosurg 26:378-382, 2012

\section{Author Contributions}

Conception and design: Bojanowski. Acquisition of data: all authors. Analysis and interpretation of data: all authors. Drafting the article: Bojanowski, Fournier. Critically revising the article: all authors. Reviewed submitted version of manuscript: all authors. Approved the final version of the manuscript on behalf of all authors: Bojanowski. Administrative/technical/material support: Bojanowski. Study supervision: Bojanowski.

\section{Supplemental Information Videos}

Video 1, Media Player. http://mfile.akamai.com/21490/wmv/ digitalwbc.download.akamai.com/21492/wm.digitalsource-naregional/jns14-1004_video_1.asx.

Video 1, Quicktime. http://mfile.akamai.com/21488/mov/ digitalwbc.download.akamai.com/21492/qt.digitalsource-global/ jns14-1004_video_1.mov.

Video 2, Media Player. http://mfile.akamai.com/21490/wmv/ digitalwbc.download.akamai.com/21492/wm.digitalsource-naregional/jns14-1004_video_2.asx.

Video 2, Quicktime. http://mfile.akamai.com/21488/mov/ digitalwbc.download.akamai.com/21492/qt.digitalsource-global/ jns14-1004_video_2.mov.

Video 3, Media Player. http://mfile.akamai.com/21490/wmv/ digitalwbc.download.akamai.com/21492/wm.digitalsource-naregional/jns14-1004_video_3.asx.

Video 3, Quicktime. http://mfile.akamai.com/21488/mov/ digitalwbc.download.akamai.com/21492/qt.digitalsource-global/ jns14-1004_video_3.mov.

Video 4, Media Player. http://mfile.akamai.com/21490/wmv/ digitalwbc.download.akamai.com/21492/wm.digitalsource-naregional/jns14-1004_video_4.asx.

Video 4, Quicktime. http://mfile.akamai.com/21488/mov/ digitalwbc.download.akamai.com/21492/qt.digitalsource-global/ jns14-1004_video_4.mov.

\section{Correspondence}

Michel W. Bojanowski, Division of Neurosurgery, Centre Hospitalier de l'Université de Montréal, 1560 Rue Sherbrooke Est., Montreal, QC H2L4M1, Canada. email: michel.bojanowski. chum@ssss.gouv.qc.ca. 